\title{
The need for interdisciplinary research on exponential technologies and sustainability (review version)
}

\author{
Marc Alier, María José \\ Casany \\ Universidad Politécnica de \\ Catalunya - BarcelonaTech \\ Campus Nord, Omega Building \\ Jordi Girona 1-3, 08034, \\ Barcelona, Spain \\ (+34) 934137174 \\ \{ludo,mjcasany\}@essi.upc.edu
}

\begin{abstract}
Technology has a clear influence on the way we live, our culture and how society functions, and last but not least our environment. At a moment when the transformational factor of technology is accelerating at an exponential pace, it is really important to reflect the direction that we want this acceleration to go.

In this paper we present some of the factors relevant to this mater: 1) the influence of technology in the society and the environment. 2) The acceleration of some technologies that have tipped and are tipping in the 20th and 21th century. 3) The problem of sustainability when exponential growth is applied to a scenario with lineal growth of resources. 4) The opportunity that represent exponential technologies to fix current humanities difficulties. And 5) technology, exponential or not, is not enough to fix the problems humanity is facing since the problems are embedded in the culture that is fueling the development of the technology.
\end{abstract}

Finally we conclude that the direction that technology will take will be determined ultimately by the society's prevalent culture, and to make an influence in the culture we need not only technologists but also humanists to enter in this kind of discussions and research.

\section{CCS Concepts}

- Computing Industry Sustainability

- Computing Profession Codes of ethics Employment issues.

\section{Keywords}

Impact of Technology, Sustainable Development, Exponential Technologies.

\section{INTRODUCTION}

History is often told as the unfolding of events and dates: battles, lives of kings and queens, the rise and fall of empires and republics, conquests and discoveries of new lands, etc. But historians also pay detailed attention to the technologies and artifacts used by every culture in the past. The available technology and (philosophical or scientific) knowledge has always determined how people live.

Stepping it up a notch, the reductionist theory of Technological determinism states that: a society's technology determines the development of its social structure and cultural values. Karl Marx's theoretical framework was grounded in the perspective that changes in technology, and specifically productive technology, are the primary influence on human social relations and organizational structures, and that social relations and cultural practices revolve around the technological and economic base of a given society. According to Smith \& Marx (1994) [19] this view of the role of technology in society has become embedded in contemporary culture.

Since the beginning of recorded history, technology has evolved at a very slow pace, and its adoption has also been slow and with uneven dissemination. This is true to a point where we can find that some technologies and scientific discoveries have occurred several times in different places. For example, agriculture was developed independently in several places around the globe and in different points in time.

But since the (re)invention of the movable type printing press by Johanes Guttenberg in 1439 and the beginning of the age of discoveries (or imperial conquests) by European kingdoms, scientific and technological discoveries started to develop and disseminate at a faster pace.

In its essay "Future Shock" [21] Alvin Toffler stated that the technological change and its effects on society are accelerating. As a consequence of this accelerated pace of technological (and scientific) change, the way of living in a society changes radically, several times, during the lifespan of one person. While a person up to the 1700's would not be shocked if she was to be time transported 100 years ahead in time. A person in the 1870's would be shocked if she was to emerge in 1920 and really astonished if she time traveled to 1970 . However people born in 1870 did actually time traveled during their lives to 1970, if the lived up to 
100 years. And they died in a world they would not have recognized when they where young.

The multiplicative factor of technology is a useful concept to explain the potential impact that a technology can have on a society and the environment where humans live. Developed by Miquel Barceló [3] the multiplicative factor is equivalent to the increase of productivity we get when a technology is used compared with the yield we got with previous practices.

If Toffler observation on the acceleration of technological change it would mean that Barceló's multiplicative factor of a technology is to increase at an accelerating pace. We believe this case to be true. And we will try to showcase it with an example with the most ubiquitous and old technology we can find: Agriculture.

In this paper we present some of the factors relevant for the analysis of the role of technology in the development of our society and its interaction with the problem of Sustainable Development: 1) the influence of technology in the society and the environment. 2) The acceleration of some technologies that have tipped and are tipping in the 20th and 21th century. 3) The problem of sustainability when exponential growth is applied to a scenario with lineal growth of resources. 4) The opportunity that represent exponential technologies to fix current humanities difficulties. And 5) technology, exponential or not, is not enough to fix the problems humanity is facing since the problems are embedded in the culture that is fueling the development of the technology.

\section{AN EXAMPLE OF TECHNOLOGY WITH INCREASING MULTIPLICATIVE FACTOR}

Neolithic revolution happened with the introduction of agriculture. A new technology that allowed such a multiplicative factor on the food yield per surface of land that changed the way humans lived, from itinerant hunter-gatherers to sedentary (or semi sedentary) farmers. Current research points to an agricultural demographic transition (ADT) than consistently occurs in huntergatherer societies when agriculture and its food surplus are introduced [6].

The ADT allowed for the creation of ever-growing settlements, war over the control of fertile lands, specialization of labor and the appearance of cities, kingdoms and the first empires. It also had a heavy impact in the environment as humans started to cut down forests to get arable land and pastures, changed the course of rivers for irrigation etc.

We can say without a doubt that the agricultural revolution changed in an irreversible manner the way humans lived and the environment. And we are talking about a technology that, at the time, would have a multiplicative impact in the order of 10 .

But agriculture is an evolving practice. Slowly but steadily agriculture has been improving its yields, adaptability to different kinds of soil and climate, resilience to variability in weather and resistance to pests. Among the improvements made to agriculture over time is noteworthy the British revolution of the agriculture in the 1700 's.
British Agricultural revolution

\begin{tabular}{|c|c|c|c|c|c|c|}
\hline \multicolumn{7}{|c|}{ Evolution of Crop Yield net of Seed (bushels per acre) } \\
\hline Year & Wheat & & & Oats & $\begin{array}{l}\text { Peas } \\
\text { beans }\end{array}$ & Growth \\
\hline 1550-1599 & 7.88 & 9.21 & 8.4 & 7.87 & 7.62 & -0.16 \\
\hline $1600-1649$ & 10.45 & 16.28 & 11.16 & 10.97 & 8.62 & -0.11 \\
\hline $1650-1699$ & 11.36 & 14.19 & 12.48 & 10.82 & 8.39 & 0.64 \\
\hline $1700-1749$ & 13.79 & 14.82 & 15.08 & 12.27 & 10.23 & 0.7 \\
\hline 175 & 6 & 17.87 & 21.88 & 20.9 & 14.19 & 0.37 \\
\hline 1800 & 23.16 & 19.52 & 25.9 & 28.37 & 17.85 & 0.63 \\
\hline $1850-1899$ & 26.69 & 26.18 & 23.82 & 31.36 & 16.3 & - \\
\hline |ltipl| & 3 & 2.8 & 2.8 & 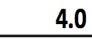 & & \\
\hline
\end{tabular}

Table 1. British Agricultural Revolution. Evolution of Crop Yield net of Seed.

The British revolution of agriculture originated with the introduction of the inventions by Jethro Tull (1674-1741) (horse drawn drill plows, seeding machines and hoes), plus other innovations like improvements on transportation and legal exclusion (the removal of common rights to establish exclusive ownership of land). These improvements caused and increase in the crop yields by a factor of 2.5 to 3 see Table 1 [1-2].

But the improvement of productivity to agriculture in the British revolution of agriculture is not only limited to a crop yields increase, but also to a significative decrease in the amount of labor it takes. As an example let's look at Table 2, where we can see how the percentage of labor force dedicated to farming decreased in the US from $80 \%$ in 1810 to $42 \%$ in 1890 as the practices introduced in the British revolution of agriculture where adopted [16].

We can argue that the industrial revolution could not have happened without the previous revolution in agriculture. The food surplus and less labor required by agriculture meant that the country could spare a lot of peasants that would become the first waves of labor force for the factories.

As for the multiplicative factor of the agriculture we can see that has over time has been experiencing significant increases. In the 20th century a number of technologies - tractors, chemical fertilizers, mutagenic modifications, GMO's, etc. - have compounded increasing the multiplicative factor of agriculture to a point where a really small percentage of the population is able to feed up to 7 billion humans. Its impact on the environment is also multiplied by a similar factor, and compounded with the impact of other technologies leading to the current crisis with climate change.

\begin{tabular}{c|r|r} 
Year & Labor force & Farmers \\
\hline 1810 & 2,330 & $80.90 \%$ \\
1840 & 5,660 & $63.10 \%$ \\
1860 & 11,110 & $54.90 \%$ \\
1890 & 23,320 & $42.70 \%$ \\
1920 & 41,610 & $25.90 \%$ \\
1940 & 56,250 & $17.00 \%$
\end{tabular}


Table 2. Percentage of labor force working on agriculture in the US (labor force in thousands).

Agriculture has shaped over the last 10.000 years the way live, the environment and has meant continuity or extinction for thousands of species. Not bad for a technology that once had a multiplicative factor of 10 or so, but that has been increasing over time. And in the last centuries is showing that this increment is not linear but rather exponential.

\section{THE PACE OF TECNOLOGICAL CHANGE}

According to Ray Kurzweil the pace in which technological change is accelerating is exponential. In his essay "The law of accelerating returns" in 2001 Kurzweil stated that "An analysis of the history of technology shows that technological change is exponential (...) So we won't experience 100 years of progress in the 21 st century — it will be more like 20,000 years of progress (at today's rate)" [15].

Kurzweil sees technology as an evolutionary process: "Evolution applies positive feedback (...) from one stage of evolutionary progress $(\ldots)$ to create the next stage. As a result, the rate of progress of an evolutionary process increases exponentially over time." [15]. Hence the returns of an evolving technology provide accelerating returns.

It's impossible tot talk about Kurzweil's evolutionary exponential technologies without mentioning Moore's law. As the reader will already know Gordon Moore, Fairchild's R\&D director, stated in 1965 that the density of transistors was doubling every 18 months and would keep doing so for the foreseeable future. There's some controversy around Moore's law: Some keep on predicting that Moore's Law will stop working in the near future (and failing so far). Others say that Moore's Law is a selffulfilling prophecy, since the industry adjusts its plans to meet Moore's Laws predictions $[4,18,20]$.

But Ray Kurzweil dug on the history of computing and found out that Moore's Law had been at work alt least since 1900, before electronic computers even existed. Kurzweil estimated the number of "calculations per second per $\$ 1,000$ " performed by turn-of-the-century analog machines, by mechanical calculators, and later by the first vacuum tube computers and extended the same calculation to modern semiconductor chips. He established that this ratio has been increasing exponentially for the past 109 years. See Fig 3.

Since the progression had been operating for 65 years before Moore's prediction, we are not looking at a self-fulfilled prophecy but at another kind of phenomena.

In accordance with Kurzweil's vision of technology as an evolutionary process, the curve drawn by Kurzweil transects five different technological paradigms of computation: electromechanical, relays, vacuum tubes, transistors and integrated circuits. Kurzweil sees an unobserved constant operating in five distinct paradigms of technology for over a century as proof of his techno-deterministic view.

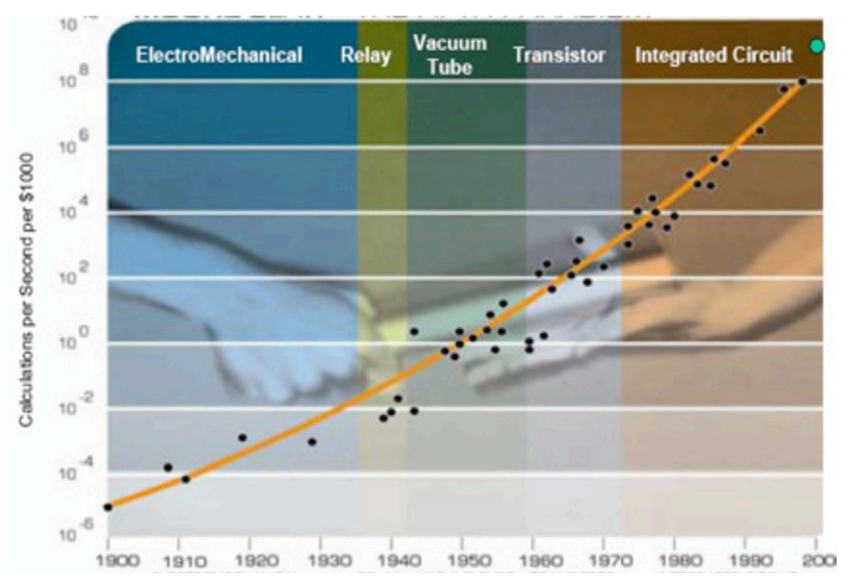

Figure 3. Calculations per second performed per $\$ 1.000$ technological evolution since 1900.

\section{THE CONSECUENCES OF EXPONENTIAL CHANGE}

On 1972 the Club of Rome published the report "The Limits to Growth: A Report for the Club of Rome's Project on the Predicament of Mankind." (LtG form now on) [17]. The LtG report, based on a computer simulation of exponential economic and population growth within an environment with finite resources, presented a model based on five variables: world population, industrialization, pollution, food production and resources depletion.

The variables are considered to grow exponentially, while the ability of -+to increase resources availability is only linear. The authors intended to explore the possibility of a sustainable feedback pattern that would be achieved by altering growth trends among the five variables. Two of the scenarios (named Standard Run, Comprehensive Technology) saw "overshoot and collapse" of the global system by the mid to latter part of the 21 st century, while a third scenario resulted in a "stabilized world." See in the Fig 4. the $\mathrm{LtG}$ projections for food per capita and the prediction of collapse in mid 21 th century [22] compared with the observed data.

The two "overshoot and collapse" scenarios of the LtG report are consistent with the theories of Jared Diamond [8] on the collapse of pre-colonial societies in island of the pacific like Easter Island. What the LtG report puts over the table is the ominous possibility and probability that our worldwide society can follow the same fate, on a global scale.

Needless to say the models that warn about the dangerous consequences of climate change, compound with the scenarios of the LtG in a scary way. Despite what climate change deniers and those who fund them may say, we - humanity as a species - have a problem in our hands. 


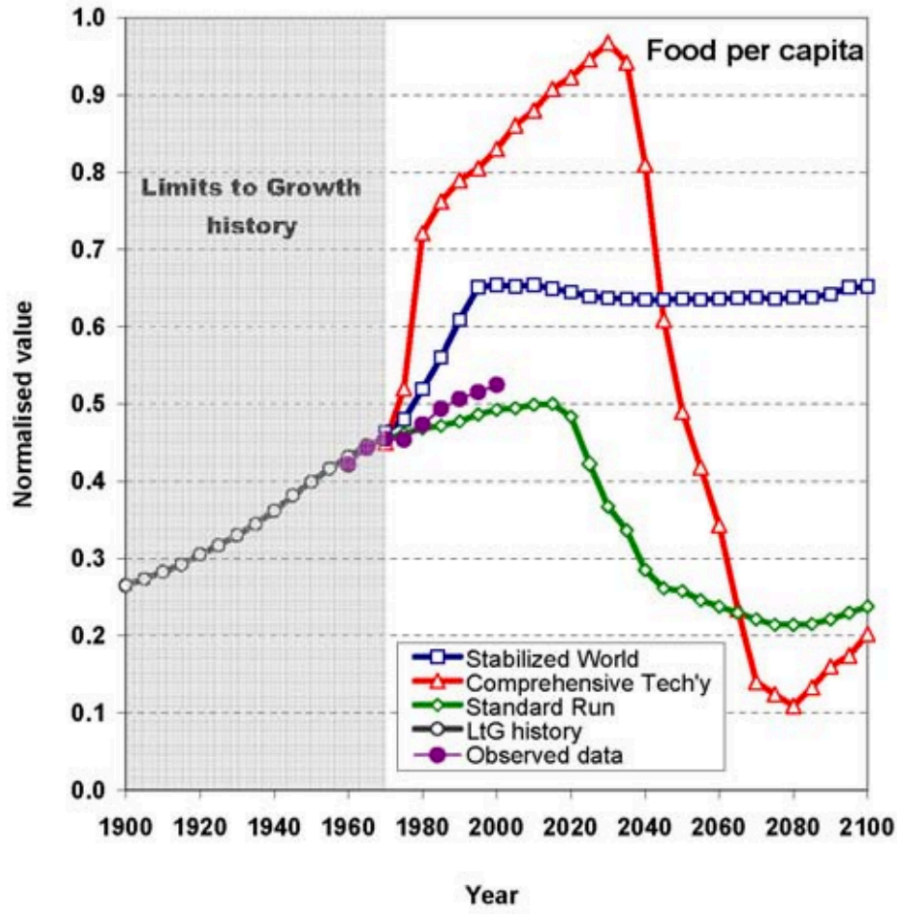

Figure 3. Comparison of observed data (solid circles) for food per capita with the LtG (Limits To Growth) model output for each scenario). The calibrated model output over 1900-1970 is shown with open circles.

\section{THE RAISE OF THE TECHNO OPTIMISTS}

\subsection{Abundance}

Peter Diamandis, partner with Kurzweil founding the Singularity University in 2008, believes that exponential technologies have the potential to solve all of the humanities problems by creating "abundance for everyone", as he explains in his book "Abundance, the future is better than you think." cowritten with Steven Kotler and published in 2012 [5,7,13].

Diamandis presents an argument based on his 6 D's for the creation of Abundance.

- Digitized: Anything that becomes Digitized takes off at the accelerated pace of Moore's Law. For example photography.

- Deceptive: When something is Digitized, at first its growth is Deceptive due to the linear like pace of growth in the first stages of an exponential curve. In the example of Photography Kodak, the creator of digital sensors, failed to take advantage of the new technology because its initial Deceptive underperformance.

- Disruptive: The existing market for a product or service is disrupted by the new market of an exponential technology. Which is consistent with the example of photography.
- Demonetized: Money is removed from de equation as the new technology becomes cheaper, often to the point of becoming free. In the case of photography the marginal cost of taking a digital photo is zero.

- Dematerialized: Separate physical products are removed from the equation. Cameras come "for free" with other devices like smartphones.

- Democratization: Once something is digitized more people can have access to it.

These principles are applied into industry with a series of practices that transform organizations into what Ismail Salim calls Exponential Organizations [12].

\subsection{ICT 4D}

The past 5 decades witnessed a heightened concern over environmental degradation. Of the various options open to society to reduce the environmental burden, technology is widely considered as the most attractive. Whether technology alone will be sufficient to achieve an environmentally sustainable future is unclear. But, the idea of using ICT to make the world more sustainable is not new. It has its origins in the fourth Annual Symposium of the American Society for Cybernetics, held in Washington, D.C. in 1970, and published its proceedings under the title "Cybernetics, Artificial Intelligence, and Ecology" [1011].

Since 1990s several fields of applied research have been created to connect the two worlds of ICT and sustainability. Many of these fields usually combine methods from disciplines of computing and communications with methods from environmental or social sciences. Some of these research fields are ICT for sustainability (ICT4S), environmental informatics, Green ICT, ICT for development (ICT4D) etc.

\section{A PROBLEM THAT LIES IN THE SYSTEM}

Naomi Klein does not agree with the vision of Diamandis. "Some people believe in technological innovation solving our big social problems, but that's magical thinking." says in her book "This changes everything: Capitalism vs the climate" [9]. For Klein and other authors claim that only a global mass movement may be effective to change the tendencies that cause climate change and has humanity in the "overshoot and collapse" described in LtG $[9,14]$.

For Klein the solution requires a non-violent, global movement to "express our love and indignation, set goals, strategize, make sacrifices, and (...) force governments to rein in corporations and reorient the economy". Klein advocates for a decisions to be made democratically, not by elites or bureaucrats, according to what we collectively value and our understanding of right and wrong, and what we owe to one another based on our shared humanity and the equal rights of all people.

Klein sees climate change is the result of a system in action: the capitalist system, which also results in inequity and many injustices (at all scales, from individuals to countries). Changing the system is challenging because the system is based and feeds back to the dominant ideology, which supports the system's destructive operations. "For example, the culture leads us to 
define ourselves by what we buy, worship wealth and fame for their own sakes".

\section{CONCLUSIONS}

The present authors don't see a contradiction in the positions of the founders of the Singularity University and the work of Naomi Klein. The issue at hand is extremely complex and broad: the future of humanity.

In this paper we have presented some of the factors we, the authors, believe to be relevant for our argument: 1) the influence of technology in the society and the environment. 2) The acceleration of some technologies that have tipped and are tipping in the 20th and 21th century. 3) The very imminent problem of sustainability presented in LtG. 4) the opportunity for "abundance" that represent exponential technologies. And 5) Technology, exponential or not, is not enough to fix the problems humanity is facing: to avoid "overshoot and collapse" (aka. the need to adopt a global sustainable development model) and prevent the potentially catastrophic effects of climate change.

The technology grows exponentially but is steered in the direction determined by the prevalent culture of the society. Hence the change in the current neoliberal capitalist system Klein proposes is needed to steer the exponential development of technologies in the right direction. For this change to happen we need to see a shift in culture and worldview, now heavily influenced by the trends that have caused the current problems. Technologists are not best suited to lead this change in cultural views, since the ones in the field of humanities have performed this task so far. So the task must lie at hand of interdisciplinary teams both with technologists and humanists.

\section{REFERENCES}

[1] Armstrong, J.S., 1986. The ombudsman: research on forecasting: A Quarter-Century Review, 19601984. Interfaces, 16(1), pp.89-109.

[2] Armstrong, J.S., 1999. Forecasting for environmental decision making. Tools to aid environmental decision making, pp.192-225.

[3] Barceló, M. and other authors. 2000. 10 Impactes de la ciència al segle XX". Eumo Editorial, ISBN 978-84-7602569-7.

[4] Berman, A. and Dorrier, J. (2016). Technology feels like it's Accelerationg - Because it actually is. SingularityHub. Available

at: https://singularityhub.com/2016/03/22/technology-feels-likeits-accelerating-because-it-actually-is/ (accessed 29/6/2017)

[5] Briggs, B., Shingles, M. 2015. Exponentials. Deloitte University Press. Available at: https://dupress.deloitte.com/dup-us-en/focus/techtrends/2015/tech-trends-2015-exponential-technologies.html (accessed 29/6/2017)
[6] Bocquet-Appel, J.P., 2011. The agricultural demographic transition during and after the agriculture inventions. Current Anthropology, 52(S4), pp. S497-S510.

[7] Diamandis, P.H. and Kotler, S., 2012. Abundance: The future is better than you think. Simon and Schuster.

[8] Diamond, J., 2005. Collapse: How societies choose to fail or succeed. Penguin.

[9] Foster, J.B., 2002. Ecology against capitalism. NYU Press.

[10] Hilty, L.M., 2011. Information technology and sustainability: Essays on the relationship between information technology and sustainable development. BoDBooks on Demand.

[11] Hilty, L.M. and Aebischer, B., 2015. Ict for sustainability: An emerging research field. In ICT Innovations for Sustainability (pp. 3-36). Springer, Cham.

[12] Ismail, S., 2014. Exponential Organizations: Why new organizations are ten times better, faster, and cheaper than yours (and what to do about it). Diversion Books.

[13] Kelly, K., 2017. The inevitable: understanding the 12 technological forces that will shape our future. Penguin.

[14] Kemp, R., 1994. Technology and the transition to environmental sustainability: the problem of technological regime shifts. Futures, 26(10), pp.1023-1046.

[15] Kurzweil, R., 2005. The singularity is near: When humans transcend biology. Penguin.

[16] LeberGott, S. 1966. Labor Force and Employment 18001960. Output, Employment, and Productivity in the United States after 1800, from the National Bureau of Economic Research. NBER.

[17] Meadows, D.H., Club of Rome, 1972. The Limits to Growth: A Report for the Club of Rome's Project on the Predicament of Mankind. Earth Island, London, UK.

[18] Powell, J.R., 2008. The quantum limit to Moore's law. Proceedings of the IEEE, 96(8), pp.1247-1248.

[19] Smith, M.R. and Marx, L. eds., 1994. Does technology drive history?: The dilemma of technological determinism. Mit Press.Vancouver.

[20] Thompson, S.E. and Parthasarathy, S., 2006. Moore's law: the future of $\mathrm{Si}$ microelectronics. Materials today, 9(6), pp.20-25.

[21] Toffler, A., 1990. Future shock. Bantam.

[22] Turner, G.M., 2008. A comparison of The Limits to Growth with 30 years of reality. Global environmental change, 18(3), pp.397-411. 